\title{
Assessment of the Sub-acute Toxicity Profile of Vitex doniana (Sweet) Leaf Fractions on Albino Rats
}

\author{
O. S. Onwukwe ${ }^{1^{*}}$, J. N. Ukwuani ${ }^{1}$, A. O. Onyemelukwe ${ }^{1}$, N. C. Azubuike ${ }^{1}$ \\ A. C. Onuba ${ }^{2}$, O. C. Ogu ${ }^{1}$, O. F. Odo ${ }^{3}$ and P. U. Achukwu ${ }^{1}$ \\ ${ }^{1}$ Department of Medical Laboratory Sciences, Faculty of Health Sciences and Technology, \\ College of Medicine, University of Nigeria, Enugu Campus, Nigeria. \\ ${ }^{2}$ Department of Veterinary Surgery and Radiology, Faculty of Veterinary Medicine, \\ University of Nigeria, Nsukka, Nigeria. \\ ${ }^{3}$ Department of Histopathology, Enugu State University Teaching Hospital, Parklane Enugu, Nigeria.
}

Authors' contributions

This work was carried out in collaboration among all authors. Authors OSO and JNU designed the protocols, performed the investigations in the study, collected the data and drafted initial manuscript. Author AOO performed the histological analysis. Author NCA assisted in data collection, performed the statistical analysis and proof read initial manuscript draft. Author ACO assisted with the animal sacrifice, sample collection and necropsy. Authors OCO and OFO contributed to literature search. Author PUA conceptualized and supervised the study and critically reviewed the literature. All authors read and approved the final manuscript.

Article Information

DOI: 10.9734/ARRB/2020/v35i230192 Editor(s):

(1) Dr. David E. Martin, Martin Pharma Consulting, LLC and DFH Pharma Inc., USA.

Reviewers:

(1) Sandeep Onkar Waghulde, University of Mumbai, India. (2) Aba-Toumnou Lucie, University of Bangui, Central African Republic. Complete Peer review History: http://www.sdiarticle4.com/review-history/55925

Original Research Article

Received 02 February 2020

Accepted 09 April 2020

Published 14 April 2020

\section{ABSTRACT}

Aim: To evaluate the sub-acute toxicity profile of fractions of Vitex doniana using adult albino rats. Study Design: An experimental study that lasted for 28 days.

Place and Duration of Study: Department of Medical Laboratory Sciences and Animal House Unit, College of Medicine, University of Nigeria Enugu Campus, between January 2019 and March 2019.

Methodology: Methanol, ethyl acetate and hexane fractions of $V$. doniana were orally administered to 6 groups of animals at doses of $150 \mathrm{mg} / \mathrm{kg}$ and $300 \mathrm{mg} / \mathrm{kg}$ body weight for each fraction, for 28 days. At the end of the administration, the animals were sacrificed. Body weight 
changes, Relative Organ Weights (ROW), haematological analysis, serum biochemical assay and histopathological changes of vital organs were used to evaluate the potential toxic effects of the fractions after treatments.

Results: The fractions had no adverse effects on the body weights, ROW and gross appearance of the tissues. There were no significant changes in the haematological and biochemical parameters of the treated animals compared to the controls. Histological assessment of the excised organs also showed no overt pathological changes apart from thickened alveolar septa in the lungs of the animals that received methanol and ethyl acetate fractions.

Conclusion: The polar fractions of $V$. doniana at the doses tested did not induce any toxic changes in the treated animals.

Keywords: Vitex doniana; toxicology; ethnopharmacology; medicinal plants.

\section{INTRODUCTION}

Vitex doniana (Black Plum in English and ucha kiri in Igbo language) is a well-known plant that is widely distributed in South East Nigeria [1]. It has multiple uses as food (both leaves and fruits are edible), medicines and source of fuel. Various parts of the plants are used traditionally for the treatment of gastrointestinal disorders such as diarrhoea, haemorrhoids, constipation and dysentery [2].

Plants serve as major source of new drugs. In the process of drug discovery from plant sources, it is often necessary to determine the mechanisms of action of potential therapeutic compounds to aid proper pharmacological classification. Crude extracts of Vitex doniana have been shown to be safe at a dose of over $3000 \mathrm{mg} / \mathrm{kg}$ body weight and also to possess antiulcer activity in rodent model of ethanol and indomethacin induced gastric ulcers $[3,4]$.

Interest in cheaper, less toxic and readily available medicinal products from natural sources is on the rise. For this reason, a lot of attention has been shifted to research aimed at developing drugs from plant sources [5]. A key step in this area of research is the evaluation of the toxicity of these potential drug compounds. This study was thus designed to evaluate the toxicity profile of polar fractions of $V$. doniana using experimental animals. The aim of this study was therefore to assess the toxicity profile of the semi-purified fractions of $V$. doniana.

\section{MATERIALS AND METHODS}

\subsection{Plant Materials, Extraction and Fractionation}

Fresh leaves of Vitex doniana were collected in Enugu metropolis during the months of April and
May 2018. They were sent to the Department of Plant Science and Biotechnology, University of Nigeria, Nsukka for authentication and confirmation of identity. The leaves were then airdried under shade and grinded into fine powder using a gasoline powered mechanical grinder. The powder was weighed and stored as appropriate in sealed water and moisture proof bags.

Crude extraction was done using methanol as solvent with the aid of a Soxhlet apparatus. After complete evaporation, the extract obtained was completely dried in a rotary evaporator and stored in sterile universal bottles. A modification of the liquid-liquid solvent partitioning methods described by Aznir et al. [6] and Brusotti et al. [7] was employed. Briefly, the dried methanol extract was suspended in $500 \mathrm{ml}$ methanol: water (9:1 solution) and partitioned with equal volume of $n-$ hexane to extract the hexane fraction. The residue was again suspended in methanol: water (6:4 solution) and partitioned with $500 \mathrm{ml}$ of ethyl acetate. The methanol: water suspended residue was then evaporated to dryness to serve as the methanol fraction. While the hexane and ethyl acetate partitions were also dried to obtain their respective fractions.

\subsection{Animal Husbandry}

The experimental animals used consisted a total of nine apparently heathy male albino mice weighing between $7 \mathrm{~g}$ and $15 \mathrm{~g}$ and thirty five apparently healthy male albino rats weighing between $97 \mathrm{~g}$ and $133 \mathrm{~g}$. The animals were obtained from and housed at the Animal House Unit of the Faculty of Basic Medical Sciences, College of Medicine of the University of Nigeria. Clean wire mesh cages were used to separate the animals into groups. The animals were housed under controlled conditions of light (12 hours light/dark cycle) and room temperature (28 
$\left.\pm 2^{\circ} \mathrm{C}\right)$. They were fed ad libitum with commercial rat feed pellet (TopFeed $\AA$ limited, Ibadan, Nigeria) and had free access to clean water throughout the duration of the experiment. The animals were allowed to acclimatize for two weeks prior to the commencement of the experiments.

\subsection{Acute Toxicity}

For the acute toxicity studies, a modification of the method by Dietrich Lorke [8] for the estimation of $L_{50}$ was used with slight modifications. The experiment was carried out using mice. Three doses of the fractions were administered orally using an oral gavage to three groups of three animals each (at doses of 10 $\mathrm{mg} / \mathrm{kg}, 100 \mathrm{mg} / \mathrm{kg}$ and $1000 \mathrm{mg} / \mathrm{kg}$ body weight respectively). The animals were observed for 24 hours for signs of acute toxicity (dullness, central nervous system depression, diarrhoea and death). This was followed by a repeat administration of the doses of $1500 \mathrm{mg} / \mathrm{kg}, 2500$ $\mathrm{mg} / \mathrm{kg}$ and $3500 \mathrm{mg} / \mathrm{kg}$ body weight respectively and a further 24-hour observation for signs of toxicity.

\subsection{Sub-acute Toxicity}

Seven groups $(A-G)$ of five animals each weighing between $97 \mathrm{~g}$ and $133 \mathrm{~g}$ were used for this experiment. The treatment of the animals lasted for 28 days. The fractions were administered orally to the animals once daily using an oral gavage. The treated animals received either $150 \mathrm{mg} / \mathrm{kg}$ or $300 \mathrm{mg} / \mathrm{kg}$ body weight of the methanol fraction (Groups $A$ and $B$ ); ethyl acetate fraction (Groups C and D); and $n$ hexane fraction (Groups $E$ and $F$ ) respectively. Group $G$ served as the control and did not receive any treatment. At the end of the administration, the animals were weighed and blood samples were collected from each animal into an anticoagulated bottle (for haematological analysis - packed cell volume, total white cell count, platelet counts) and into a plain bottle (for biochemical analysis - estimation of serum levels of alanine transaminase (ALT), aspartate transaminase (AST), alkaline phosphatase (ALP), urea and creatinine). The animals were then sacrificed under chloroform anaesthesia and the stomach, liver, kidney, lungs, spleen and heart were harvested and weighed to determine relative organ weights using the formula - weight of organ/weight of animal. The harvested organs were assessed for gross pathologies and subsequently processed into paraffin blocks for histological analysis [9].

\subsection{Data Analysis}

All numerical data generated were subjected to preliminary exploratory statistics and where necessary have been expressed as mean \pm standard error of mean. The mean weights of the various groups before and after administration of fractions was recorded and presented as bar charts followed by computation of weight changes in percentage. Mean relative organ weights of all excised organs, haematological parameters and biochemical parameters of the various groups were compared. Differences between means were determined first by oneway analysis of variance (ANOVA) followed by Tukey post hoc test for multiple comparisons between the various groups. The significance level was set to $P<0.05$. Results of the analysis are presented in tabular and graphic formats as suitable.

\section{RESULTS}

\subsection{Oral Acute Toxicity Study}

Following the administration of up to $3500 \mathrm{mg} / \mathrm{kg}$ body weight (bw) of the fractions to the mice, no deaths or signs of distress were noticed within 24 hours of administration. Further observation for another 24 hours revealed no signs of distress or toxicity.

\subsection{Gross Appearance of Harvested Organs}

The kidney, heart, liver, lung spleen and stomach of the animals from the various treatment groups after 28 days of oral administration of the various fractions did not reveal any overt pathologies with all the organs appearing normal.

\subsection{Changes in Body Weight of Animals and Relative Organ Weights}

Fig. 1 is a bar chart showing the change in body weights of the animals in different fraction administration over a 28 day period of oral administration. All the animals in the treatment and control groups gained weight during the period of administration. The weight changes were converted to percentages and it was observed that all the treated groups, except group $D$, had higher percentage weight gains than the control group. Group A (150 mg/kg bw methanol fraction) had the highest percentage weight gain (78\%) while Groups D (300 mg/kg 
bw ethyl acetate fraction) had the lowest percentage weight gain (64\%).

The mean relative organ weights of the animals in the various treatment groups is presented in Table 1. After subjecting the weight data to analysis of variance and comparing the various groups, no statistically significant difference was observed between the various treatment groups.

\subsection{Effect of Administration of Fractions on Some Haematological and Biochemical Parameters}

The effect of oral administration of the various fractions on some haematological parameters is shown in Table 2. The mean total white cell count for animals in Group $\mathrm{E}$ that received 150 $\mathrm{mg} / \mathrm{kg}$ body weight (bw) of the hexane fraction was significantly lower than those of Group B (300 mg/kg bw methanol fraction, $P=0.023$ ) and Group C (150 mg/kg bw ethyl acetate fraction, P $=0.014)$. All other parameters assessed did not significantly differ within the test groups and between test groups and control groups.

Table 3 shows the mean serum levels of some biochemical parameters assessed after 28 days of administering the fractions to test animals. There was no statistically significant difference in mean serum levels of urea, creatinine, AST, and ALT $(P>0.05)$. However, the animals in Group $C$
(150 $\mathrm{mg} / \mathrm{kg}$ bw ethyl acetate fraction) had significantly lower serum ALP level when compared to Group F (300 mg/kg bw hexane fraction, $P=0.015)$ and Group $A(150 \mathrm{mg} / \mathrm{kg}$ bw methanol fraction, $P=0.018)$. Generally the fractions seem to cause an increase in the serum levels of ALP of all treatment groups except Group C, when compared to the control group even though it was not statistically significant $(P$ $>0.05)$.

\subsection{Effects of the Administration of Fractions on the Histology of Excised Organs}

Fig. $2(A-F)$ are micrographs of normal tissue sections of the kidney, heart, liver, lungs, spleen and stomach from the control group. Fig. 3 (A F) are representative tissue micrographs of animals in the various treatment groups showing observed pathological changes. The kidney, heart and spleen sections of all treated animals appear normal. However, the liver sections of animals in Group B, C and D (that received 300 $\mathrm{mg} / \mathrm{kg}$ body weight MEVD, $150 \mathrm{mg} / \mathrm{kg}$ body weight EAVD and $300 \mathrm{mg} / \mathrm{kg}$ body weight EAVD showed congested central veins and mild periportal infiltration by inflammatory cells. Also, the lung sections of animals in group $A$ appear to have mildly thickened alveolar septa while the animals in Groups $E$ and $F$ had moderately thickened alveolar septa.

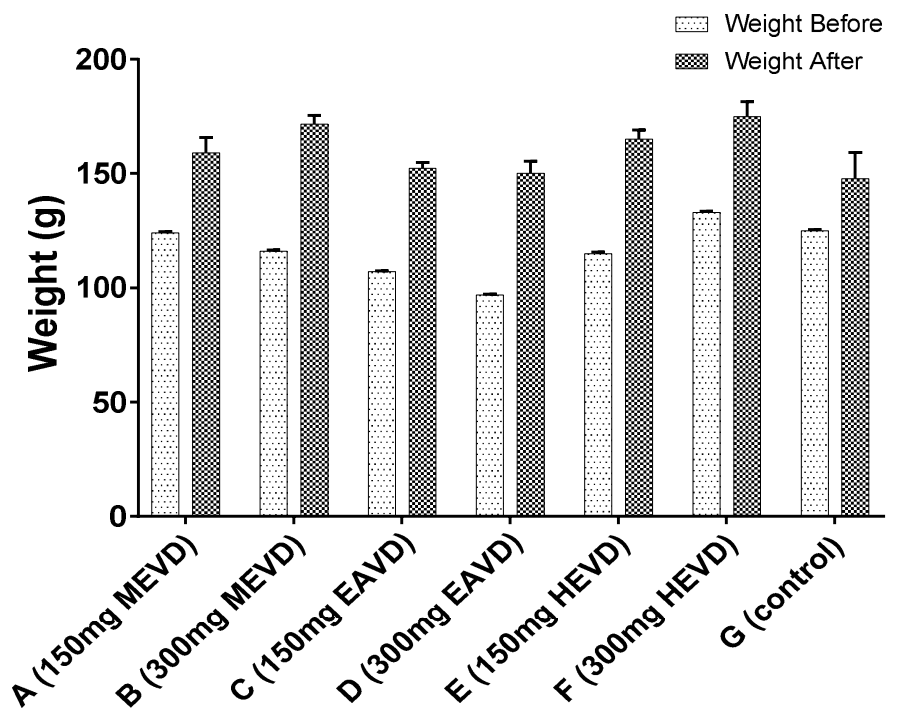

Fig. 1. Bar chart showing the changes in body weight of animals before and after a 28 day oral administration of the various fractions

Each bars represent the mean for each group; the whiskers represent SEM 
Table 1. Relative organ weights of the animals (in grams) in the various fraction treatment groups

\begin{tabular}{|c|c|c|c|c|c|c|c|c|c|}
\hline \multirow[t]{2}{*}{ Organs } & \multicolumn{7}{|c|}{ Groups } & \multicolumn{2}{|c|}{ ANOVA } \\
\hline & $\begin{array}{l}\text { A (150 mg } \\
\text { MEVD) }\end{array}$ & $\begin{array}{l}\text { B (300 mg } \\
\text { MEVD) }\end{array}$ & $\begin{array}{l}\text { C (150 mg } \\
\text { EAVD) }\end{array}$ & $\begin{array}{l}\text { D (300 mg } \\
\text { EAVD) }\end{array}$ & $\begin{array}{l}\text { E (150 mg } \\
\text { HEVD) }\end{array}$ & $\begin{array}{l}\mathrm{F}(300 \mathrm{mg} \\
\text { HEVD) }\end{array}$ & G (control) & $\begin{array}{l}\mathbf{F} \\
\text { ratio }\end{array}$ & $\begin{array}{l}P \\
\text { value }\end{array}$ \\
\hline Heart & $0.004 \pm 0.000$ & $0.004 \pm 0.000$ & $0.004 \pm 0.000$ & $0.004 \pm 0.000$ & $0.003 \pm 0.000$ & $0.003 \pm 0.000$ & $0.004 \pm 0.000$ & 1.474 & 0.267 \\
\hline Left lung & $0.003 \pm 0.000$ & $0.003 \pm 0.000$ & $0.002 \pm 0.000$ & $0.002 \pm 0.000$ & $0.002 \pm 0.000$ & $0.002 \pm 0.000$ & $0.002 \pm 0.000$ & 2.143 & 0.123 \\
\hline Right lung & $0.004 \pm 0.000$ & $0.004 \pm 0.000$ & $0.004 \pm 0.000$ & $0.004 \pm 0.000$ & $0.004 \pm 0.000$ & $0.003 \pm 0.000$ & $0.005 \pm 0.000$ & 1.153 & 0.391 \\
\hline Left kidney & $0.004 \pm 0.000$ & $0.004 \pm 0.000$ & $0.003 \pm 0.000$ & $0.003 \pm 0.000$ & $0.003 \pm 0.000$ & $0.003 \pm 0.000$ & $0.003 \pm 0.000$ & 2.084 & 0.132 \\
\hline Right kidney & $0.004 \pm 0.000$ & $0.003 \pm 0.000$ & $0.004 \pm 0.000$ & $0.003 \pm 0.000$ & $0.004 \pm 0.000$ & $0.003 \pm 0.000$ & $0.004 \pm 0.000$ & 1.699 & 0.204 \\
\hline Spleen & $0.002 \pm 0.000$ & $0.003 \pm 0.000$ & $0.003 \pm 0.000$ & $0.003 \pm 0.000$ & $0.003 \pm 0.000$ & $0.002 \pm 0.000$ & $0.002 \pm 0.000$ & 0.871 & 0.543 \\
\hline Liver & $0.029 \pm 0.001$ & $0.031 \pm 0.001$ & $0.032 \pm 0.001$ & $0.032 \pm 0.005$ & $0.033 \pm 0.000$ & $0.030 \pm 0.002$ & $0.031 \pm 0.002$ & 0.183 & 0.976 \\
\hline Stomach & $0.014 \pm 0.002$ & $0.028 \pm 0.003$ & $0.014 \pm 0.001$ & $0.02 \pm 0.004$ & $0.027 \pm 0.002$ & $0.024 \pm 0.005$ & $0.013 \pm 0.003$ & 4.579 & 0.012 \\
\hline
\end{tabular}

Values presented are mean \pm SEM. F ratio and $P$ values are from one-way analysis of variance with significance set at $P<0.05$

Table 2. Haematological parameters of test animals after 28 days of oral administration of the various fractions of $V$. doniana

\begin{tabular}{|c|c|c|c|}
\hline \multirow[t]{2}{*}{ Groups } & \multicolumn{3}{|c|}{ Haematological parameters } \\
\hline & Packed cell volume (\%) & Total white cell count $\left(\mathrm{mm}^{-3}\right)$ & Platelet count (x 10\% /L) \\
\hline A (150 mg MEVD) & $38.00 \pm 3.49$ & $11.58 \pm 0.97$ & $39.85 \pm 3.92$ \\
\hline B (300 mg MEVD) & $47.75 \pm 5.65$ & $14.98 \pm 1.77$ & $24.03 \pm 2.99$ \\
\hline C (150 mg EAVD) & $38.75 \pm 2.39$ & $15.48 \pm 2.04$ & $30.45 \pm 2.06$ \\
\hline D (300 mg EAVD) & $37.25 \pm 1.03$ & $10.35 \pm 1.30$ & $37.55 \pm 5.25$ \\
\hline E (150 mg HEVD) & $37.25 \pm 4.07$ & $7.05 \pm 0.34^{* \mathrm{~b}, \mathrm{c}}$ & $24.55 \pm 5.28$ \\
\hline F (300 mg HEVD) & $38.00 \pm 3.39$ & $12.83 \pm 1.62$ & $25.90 \pm 4.85$ \\
\hline $\mathrm{G}$ (control) & $41.00 \pm 2.89$ & $13.77 \pm 2.51$ & $30.00 \pm 2.89$ \\
\hline \multicolumn{4}{|l|}{ ANOVA } \\
\hline F ratio & 1.133 & 3.590 & 2.343 \\
\hline$P$ value & 0.379 & 0.014 & 0.071 \\
\hline
\end{tabular}

$M E V D$ - methanol fraction of $V$ doniana, EAVD - ethyl acetate fraction of $V$ doniana, HEVD - $n$ hexane fraction of $V$ doniana. ${ }^{*}$ denotes statistically significant difference from groups corresponding to the superscript letter 
Table 3. Biochemical parameters of test animals after 28 days of oral administration of the various fractions of $V$. doniana

\begin{tabular}{|c|c|c|c|c|c|}
\hline \multirow[t]{2}{*}{ Groups } & \multicolumn{5}{|c|}{ Biochemical parameters } \\
\hline & Urea (mmol/l) & Creatinine (umol/l) & $\begin{array}{l}\text { Aspartate transaminase } \\
\text { (iu/l) }\end{array}$ & $\begin{array}{l}\text { Alanine transaminase } \\
\text { (iu/l) }\end{array}$ & $\begin{array}{l}\text { Alkaline phosphatase } \\
\text { (iu/l) }\end{array}$ \\
\hline A (150mg MEVD) & $4.57 \pm 0.25$ & $126.48 \pm 3.16$ & $184.75 \pm 13.10$ & $71.50 \pm 9.67$ & $271.50 \pm 24.12^{\dagger}$ \\
\hline B (300mg MEVD) & $5.00 \pm 0.23$ & $119.88 \pm 5.97$ & $199.50 \pm 10.38$ & $55.50 \pm 4.79$ & $223.75 \pm 23.30$ \\
\hline C (150mg EAVD) & $4.80 \pm 0.12$ & $117.65 \pm 5.96$ & $194.75 \pm 25.44$ & $57.50 \pm 5.48$ & $187.25 \pm 10.69^{\times a, f}$ \\
\hline D (300mg EAVD) & $5.00 \pm 0.09$ & $105.03 \pm 3.00$ & $218.25 \pm 36.44$ & $52.75 \pm 2.87$ & $211.25 \pm 13.49$ \\
\hline E (150mg HEVD) & $4.75 \pm 0.12$ & $108.55 \pm 3.34$ & $175.00 \pm 20.27$ & $51.00 \pm 6.20$ & $206.75 \pm 9.46$ \\
\hline $\bar{F}(300 \mathrm{mg}$ HEVD) & $4.60 \pm 0.26$ & $115.53 \pm 5.15$ & $188.75 \pm 22.21$ & $51.00 \pm 6.20$ & $211.25 \pm 13.49$ \\
\hline $\mathrm{G}$ (control) & $4.90 \pm 0.15$ & $125.93 \pm 12.49$ & $265.00 \pm 4.36$ & $55.25 \pm 4.97$ & $200.25 \pm 4.09$ \\
\hline \multicolumn{6}{|l|}{ ANOVA } \\
\hline F ratio & 0.620 & 1.622 & 2.010 & 1.274 & 3.412 \\
\hline$P$ value & 0.712 & 0.190 & 0.110 & 0.311 & 0.016 \\
\hline
\end{tabular}

MEVD - methanol fraction of V doniana, EAVD - ethyl acetate fraction of $V$ doniana, HEVD - $n$ hexane fraction of $V$ doniana. ${ }^{*}$ denotes statistically significant difference from groups corresponding to the superscript letter 

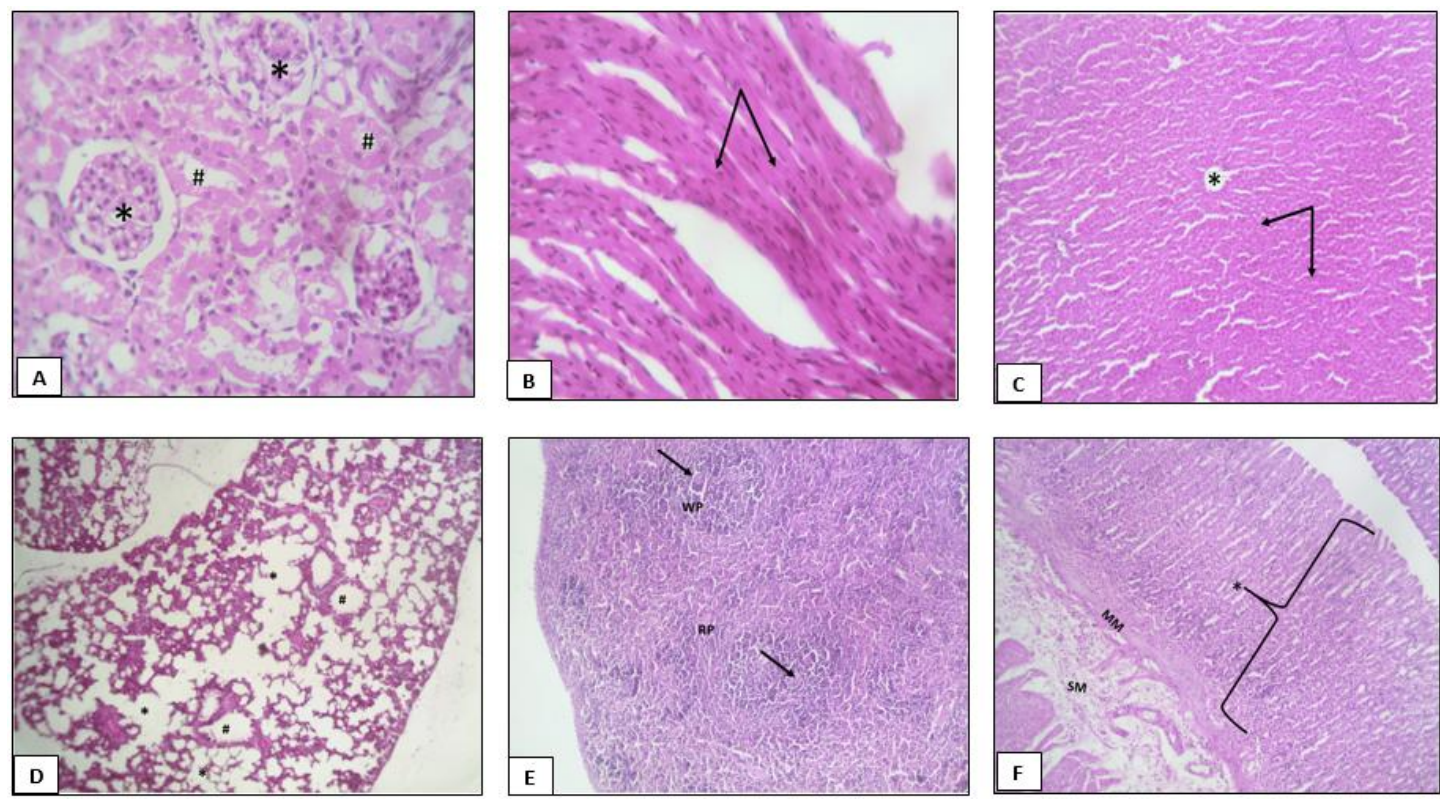

Fig. 2. Micrographs of tissue sections from control animals showing normal histological features. A - Kidney section with normal glomeruli (*) and tubules (\#); B - heart section with normal cardiac fibres (arrows); C - Liver section with normal hepatocytes (arrows) and central vein $\left({ }^{*}\right)$; D - lung section showing normal air sacs and alveolar septa $\left({ }^{*}\right)$ and terminal bronchioles (\#); E - spleen section devoid of pathological features. RP- red pulp, WP - white pulp, arrows - splenic artery; F - Stomach section showing normal epithelia $\left({ }^{*}\right)$, muscularis (M) and submucosa (SM). Stain: H\&E. Magnification: X100 - X400

\section{DISCUSSION}

Establishing safety of potential drug compounds from plants is an important step in the process of drug discovery. In the acute toxicity study, the plant fractions did not cause any deaths or visible distress to the animals up to a dose of $3500 \mathrm{mg} / \mathrm{kg}$ suggesting that the plant leaf fractions are safe for potential therapeutic use $[10,11]$.

Blood is a tissue that is highly sensitive to toxic effects making it relevant to the evaluation of toxicity [12]. In this study, no major changes were observed in the haematological parameters assessed following administration of the fractions. However, animals that received the low dose of the hexane fraction were seen to have significantly lower total white cell count. Certain medicinal plants are known to cause adverse changes to haematological parameters $[13,14]$. This decrease may thus be suggestive of a haematotoxic component within the hexane fraction. However, this observation is difficult to explain especially since the animals that received a higher dose of the fraction did not have decreased total white cell count.
In the serum biochemical analyses, no adverse changes were recorded in the serum levels of urea and creatinine in the treated animals. Both urea and creatinine are generally accepted markers of renal integrity with overt changes in either of them being a strong indication of renal injury [15]. Serum levels of enzymes such as liver amino transaminases (AST and ALT) and other enzymes such as ALP are important for the assessment of hepatotoxicity of compounds. A rise in serum levels of activity of these enzymes is often indicative of damage to the liver [16].

In this study, the serum levels of the liver marker enzymes assessed were not adversely affected in the treated animals except for those that received the low dose of ethyl acetate fraction whose serum ALP levels were significantly lower. Alkaline phosphatase (ALP) is a group of isoenzymes found in many organs including the bones, liver, intestines, kidney and placenta $[17,18]$. Given that the histological picture of the liver of animals in the group did not suggest any severe liver damage, it is possible that the reason for the decrease may be due other factors not covered in the present study. For instance, it is known that inflammatory conditions 
involving the intestinal region may give rise to changes in ALP levels especially since rats are known to have higher intestinal ALP levels than hepatic ALP levels [19].

At the end of the administration all animals were observed to have increased in weight. Changes in body weights can serve as useful indicators of toxicity [20]. However, the increased weights may have been as a result of normal physiological growth rather than a direct consequence of consuming the plant even though it is known that certain plant components induce weight changes in animals via various mechanisms $[21,22]$. In the same manner, there were no significant changes in the relative organ weights of the animals in the treatment groups compared to the control. Relative organ weight is also sensitive markers of toxicity of some substances [13]. The absence of adverse changes in organ weights by the fractions may be indicative of their safety and inability to cause abnormal growth in the organs of animals.

Both gross and histopathological assessment of the excised organs and tissue sections respectively did not reveal any overt signs of toxicity or pathology. Sections of the lungs from some of the animals showed varying degrees of thickening of the alveolar septa and inflammation. Such changes are more likely as a result of inhaled irritants or infections and not may not necessarily be as a result of fraction administration [23].
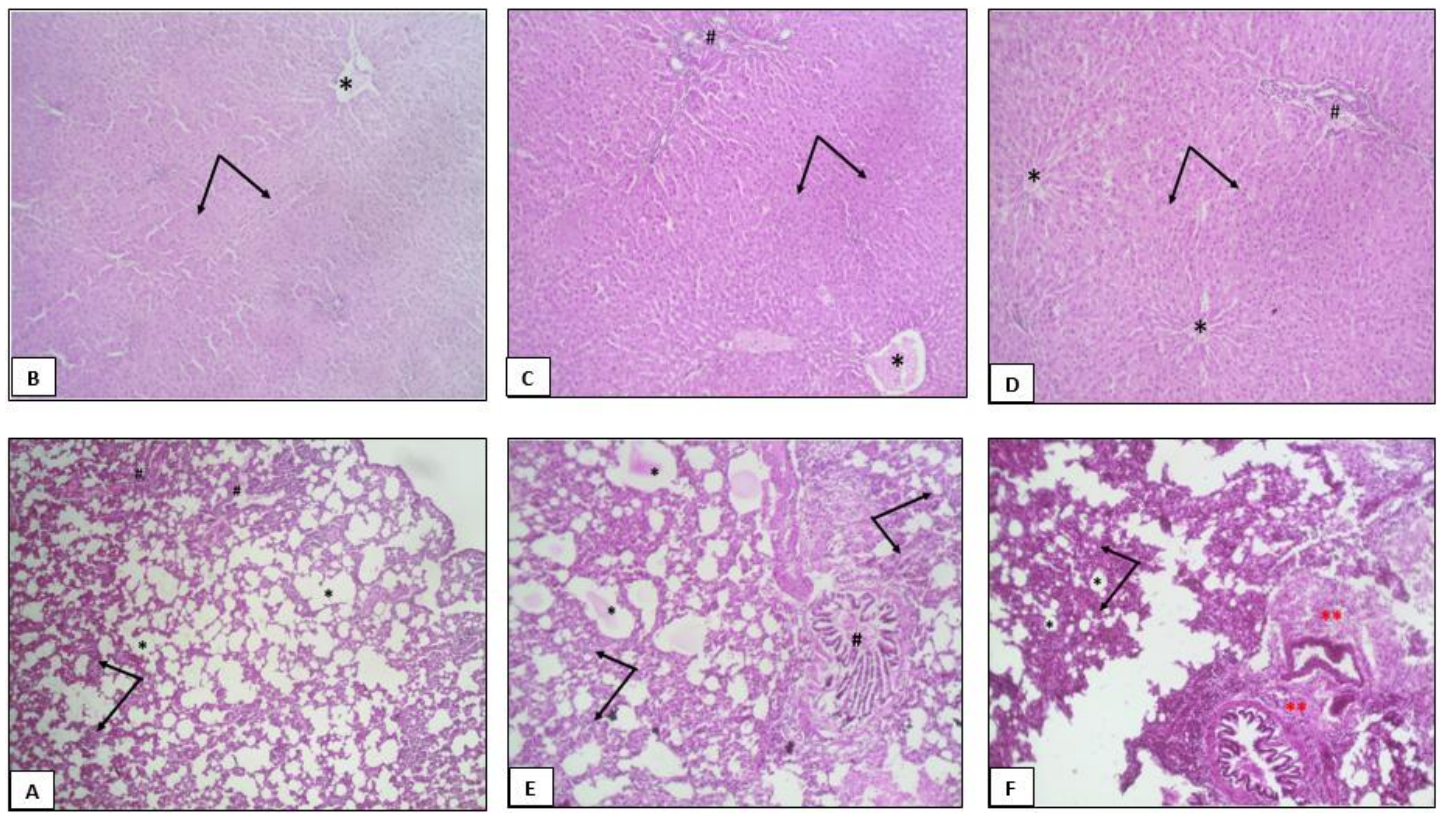

Fig. 3. Micrograph of selected liver and lung tissue sections from treated showing observed pathological changes. B - Liver section from an animal in Group B (300 mg/kg bw MEVD) the hepatocytes (arrows) are normal, central vein is mildly congested (*); C - Liver section from an animal in Group C (150 mg/kg bw EAVD) the hepatocytes (arrows) are normal, central vein is congested $\left(^{*}\right)$ and there is mild infiltration of the portal triad (\#); D - liver section from an animal in Group D (300 mg/kg bw EAVD) the hepatocytes (arrows) are normal, central vein is congested $\left(^{*}\right)$ and there is moderate peri-portal infiltration (\#); A - Lung section from an animal in Group A (150 mg/kg body weight of MEVD). The alveolar septa are slightly thickened (arrow) but the air sacs (*) and terminal bronchioles (\#) are normal; E - Lung section from an animal in Group E (150 mg/kg b.w. of HEVD). The alveolar septa (arrows) appear thickened, both the terminal bronchiole (\#) and air sacs $\left(^{*}\right)$ contains eosinophilic matter; F - Lung section from a representative animal in Group F (300 mg/kg b.w. of HEVD).

The alveolar septa (arrows) appear thickened. There is evidence of peribronchial inflammation $\left({ }^{* *}\right)$ with infiltration of inflammatory cells. The air sacs $\left({ }^{*}\right)$ appear smaller than normal. Stain: H\&E. Magnification: X100 - X400 


\section{CONCLUSION}

From these observations, it may be concluded that all three fractions of $V$. doniana can be considered safe for oral consumption up to a dose of $300 \mathrm{mg} / \mathrm{kg}$ body weight for up to a period of twenty eight days since it did not induce consistent, noticeable toxic changes to the animals tested within that time period. However the observed changes in the white cell count, ALP and liver and lung histology of some of the animals necessitates the need for cautious use of these plant leaves for medicinal purposes.

\section{ETHICAL APPROVAL}

Ethical approval for this study was obtained from the ethical committee Faculty of Veterinary Medicine, University of Nigeria Nsukka, Enugu State. Principles of laboratory animal care" (NIH publication No. 85-23, revised 1985) were followed, as well as specific national laws where applicable. All experiments have been examined and approved by the appropriate ethics committee.

\section{ACKNOWLEDGEMENTS}

The authors acknowledge the staff of Animal House of the College of Medicine University of Nigeria (UNN) who assisted with animal husbandry and guidelines on proper use of animals. They also acknowledge the staff at the Department of Pharmacognosy, Faculty of Pharmaceutical sciences UNN for their help with plant identification and fractionation.

\section{COMPETING INTERESTS}

Authors have declared that no competing interests exist.

\section{REFERENCES}

1. Agbafor $\mathrm{KN}$, Nwachukwu N. Phytochemical analysis and antioxidant property of leaf extracts of Vitex doniana and Mucuna pruriens. Biochemistry Research International. 2011;1-4.

Available:http://dx.doi.org/10.1155/2011/45 9839

2. Dadjo C, Assogbadjo AE, Fandohan B, Glèlè Kakaï R, Chakeredza $S$, Houehanou TD, et al. Uses and management of black plum (Vitex doniana Sweet) in Southern Benin. Fruits. 2012;67(4):239-248.
Available:https://doi:10.1051/fruits/201201 7

3. Steven OO, Uwadiegwu AP, Chinonyelum AN, Chukwu ND, Obianuju OA, Kingsley UI, Chekwube EB. Preliminary studies on the anti-ulcer potentials of Vitex doniana crude extracts on experimental rat model of ethanol induced gastric ulcer. Asian Pacific Journal of Tropical Disease. 2016;6(9):736-740.

Available:https://doi:10.1016/s22221808(16)61120-9

4. Onwukwe OS, Azubike NC, Eluke BC, Onyemelukwe AO, Ogu CO, Chukwu IJ, Achukwu PU. Evaluation of the antiulcer properties of aqueous and methanol extracts of Vitex doniana on indomethacin induced gastric ulcers in albino rats. Pharmacologyonline. Archive. 2018;68-74.

5. Gregory M, Divya B, Mary RA, Viji MMH, Kalaichelvan VK, Palanivel V. Anti-ulcer activity of Ficus religiosa leaf ethanolic extract. Asian Pacific Journal of Tropical Biomedicine. 2013;3(7):554-556.

Available:https://doi:10.1016/s22211691(13)60112-4

6. Azmir J, Zaidul ISM, Rahman MM, Sharif KM, Mohamed A, Sahena F, Omar AKM. Techniques for extraction of bioactive compounds from plant materials: A review. Journal of Food Engineering. 2013;117(4):426-436.

7. Brusotti G, Cesari I, Dentamaro A, Caccialanza G, Massolini G. Isolation and characterization of bioactive compounds from plant resources: The role of analysis in the ethnopharmacological approach. Journal of Pharmaceutical and Biomedical Analysis. 2014;87:218-228.

Available:https://doi:10.1016/j.jpba.2013.03 .007

8. Lorke D. A new approach to practical acute toxicity testing. Archives of Toxicology. 1983;54(4):275-287.

Available:http://dx.doi.org/10.1007/bf01234 480

9. Spencer LT, Bancroft JD. Tissue processing. Bancroft's Theory and Practice of Histological Techniques. 2013;105-123. Available:https://doi:10.1016/b978-0-70204226-3.00006-8

10. Eaton DL, Klaassen CD. Principles of toxicology. In: Klaassen, C.D. (Ed.), Casarett and Doull's Toxicology: The Basic Science of Poisons, $5^{\text {th }}$ Ed. McGraw Hill, 13. Authors: John A. Pickrell; 1996. 
Available:https://doi.org/10.1016/s03784274(96)90054-5

11. Arsad SS, Esa NM, Hamzah H, Othman F. Evaluation of acute, subacute and subchronic oral toxicity of Rhaphidophora decursiva (Roxb.) Schott extract in male Sprague Dawley rats. Journal of Medicinal Plant Research. 2013;7(41):3030-3040.

12. Mukinda JT, Syce JA. Acute and chronic toxicity of the aqueous extract of Artemisia afra in rodents. Journal of Ethnopharmacology. 2007;112(1):138144.

Available:https://doi:10.1016/j.jep.2007.02. 011

13. Babayi HM, Udeme J, Abalaka JA, Okogun JI, Salawu OA, Akumka DD, et al. Effect of oral administration of aqueous whole extract of Cassytha filiformis on haematograms and plasma biochemical parameters in rats. Journal of Medical Toxicology. 2007;3(4):146-151.

Available:https://doi:10.1007/bf03160930

14. Elgerwi A, Benzekri Z, Awaidat S, ElMagdoub A, Abusnina A, El-Mahmoudy A. Subchronic haemotoxicity and histotoxicity of Citrullus colocynthis. Journal of American Science. 2013;9(5):1-11.

15. Odo OF, Achukwu PU, Azubuike NC, Onwukwe OS, Onyemelukwe AO, Ekoh AJ. Sub-acute toxicity profile of aqueous seed extracts of Dacryodes edulis. Der Pharmacia Lettre. 2019;10(10):35-44.

16. Azubike NC, Achukwu PU, Okwuosa CN, Nwachukwu DC, Onwukwe OS, Onyemelukwe AO. Subacute toxicity profile of the leaves of Colocasia esculenta [L. Schott] in albino rats. Research Journal of Medicinal Plants [Internet]. 2016;1:10(5):340-348.

Available:http://dx.doi.org/10.3923/rjmp.20 16.340.348

17. Badgu N, Merugu R. Human alkaline phosphatases in health and disease: $A$ mini review. International Journal of Research in Pharmaceutical Sciences. 2013;4(3):371-379.
18. Sharma U, Pal D, Prasad R. Alkaline phosphatase: An overview. Indian Journal of Clinical Biochemistry [Internet]. Springer Science and Business Media LLC. 2013;29(3):269-78.

Available:http://dx.doi.org/10.1007/s12291013-0408-y

19. Amacher DE. A toxicologist's guide to biomarkers of hepatic response. Human and experimental toxicology. 2002;21(5):253-262.

Available:https://doi.org/10.1191/09603271 02ht247oa

20. Teo S, Stirling D, Thomas S, Hoberman A, Kiorpes A, Khetani V. A 90-day oral gavage toxicity study of $d$-methylphenidate and d,I-methylphenidate in spraguedawley rats. Toxicology [Internet]. Elsevier BV. 2002;179(3):183-196.

Available:http://dx.doi.org/10.1016/s0300483x(02)00338-4

21. Rhiouani H, El-Hilaly J, Israili ZH, Lyoussi B. Acute and sub-chronic toxicity of an aqueous extract of the leaves of Herniaria glabra in rodents. Journal of Ethnopharmacology [Internet]. Elsevier BV. 2008;118(3):378-386.

Available:http://dx.doi.org/10.1016/j.jep.20 08.05.009

22. Azubuike NC, Onwukwe OS, Onyemelukwe AO, Maduakor UC, Ifeorah IM, Okwuosa CN, Achukwu PU. Impact of Colocasia esculenta extract and fractions on high-fat diet-induced changes in body weight, adipose tissue and liver of rats. Pakistan Journal of Pharmaceutical Sciences. $\quad 2018 ; 31$ (5 (Supplementary)):2143.

23. Carpenter TC, Reeves JT, Durmowicz AG. Viral respiratory infection increases susceptibility of young rats to hypoxiainduced pulmonary edema. Journal of Applied Physiology [Internet]. American Physiological Society. 1998;84(3):104854.

Available:http://dx.doi.org/10.1152/jappl.19 98.84.3.1048

(c) 2020 Onwukwe et al.; This is an Open Access article distributed under the terms of the Creative Commons Attribution License (http://creativecommons.org/licenses/by/4.0), which permits unrestricted use, distribution, and reproduction in any medium, provided the original work is properly cited.

Peer-review history:

The peer review history for this paper can be accessed here: http://www.sdiarticle4.com/review-history/55925 